\title{
The incidence of male childhood Type 1 (insulin-dependent) diabetes mellitus is rising rapidly in The Netherlands
}

\author{
C. E.M. Drykoningen ${ }^{1,3}$, A. L.M.Mulder ${ }^{2,3}$, G.J. Vaandrager ${ }^{1}$, R.E. LaPorte ${ }^{4}$ and G.J.Bruining $^{3}$ \\ 1 TNO Institute for Preventive Health Care, Leiden, \\ ${ }^{2}$ Department of Medical Affairs, National Military Service Medical Examination, Kerkrade, \\ ${ }^{3}$ Department of Paediatrics, Subdivision of Hereditary, Congenital Diseases, Erasmus University and University Hospital, \\ Sophia Children's Hospital, Rotterdam, The Netherlands and \\ ${ }^{4}$ WHO Collaborating Center for Diabetes Registries Research and Training, Pittsburgh, Pennsylvania, USA
}

Summary. This study evaluates the cumulative incidence of Type 1 (insulin-dependent) diabetes mellitus in male army conscripts 0-18 (inclusive) years of age in the Netherlands (birth cohorts) over 10 years. Data from 2136 cases were retrieved from files of the conscript registry of the Royal Dutch Army. Ascertainment was sought by the capture-recapture method, achieving an average ascertainment rate of $89.7 \%$. Poisson regression modelling was used to determine the change in incidence over time. A significant non-linear increase in the incidence of insulin-dependency in the birth cohorts of 1960-1970 was found. The cumulative incidences of the early birth cohorts $1.85 / 1000$ (1960), 1.76/1000 (1961),
$1.11 / 1000$ (1962) were considerably lower than of the later birth cohorts 1.96/1000 (1968), 2.11/1000 (1969), 2.12/1000 (1970). Overall the risk of Type 1 diabetes increased on the average $4.4 \%$ with each annual birth cohort. Only for the 1962 birth cohort was a significant dip in the incidence observed. The results indicate a rapidly increasing incidence of diabetes in males in the Netherlands consistent with the concurrent rapid rise in Northern Europe, found in both sexes.

Key words: Type 1 (insulin-dependent) diabetes mellitus, military medicine, incidence, cohort studies, longitudinal studies, child.
During the past decades, surveys in the Nordic countries have found an increase in risk for Type 1 (insulin-dependent) diabetes mellitus [1-3] with an annual change of approximately $3.3 \%$, in Finland $2.4 \%$ [4]. Studies in North America however, have demonstrated little long-term variation in the incidence of diabetes [5]. World-wide, there are few data available to evaluate temporal trends for the risk of developing diabetes in the young. In the Netherlands the incidence during 1978-1980 (inclusive) was $11.6 / 100,000$ for males, $0-19$ years of age [6]. The current study looked for temporal trends of the incidence of Type 1 diabetes in the 1960-1970 birth cohorts of male army conscripts in the Netherlands [7]. Following the approach by Green and associates $[8,9]$ in Denmark, the army conscript registry was chosen, as all males aged 18 are eligible for military service by law and most participate in a standardized medical screening programme to evaluate their fitness for service. Thus, a nation-wide source over time is available, in as much as the screening procedures were constant over time.

\section{Subjects and methods}

Data were obtained from the files of the National Military Service Medical Examination Office for male conscripts born in the years
1960-1970. The military authorities required that while obtaining the data, confidentiality of the conscripts was respected. The files contain information written by the examining military physician on a standardized form. The medical procedures and forms were introduced in 1955 and are still in use. At the medical examination a special code was given by the military physician to all 18-year-old males who have "diabetes mellitus" and/or "glucosuria". In the large majority, a diagnosis of insulin-dependency was based on written evidence $(94 \%)$ from either the paediatrician or the internist treating the conscript, or from his general practitioner. In the Netherlands all young Type 1 diabetic patients are treated by a paediatrician or an internist [6] and the general practitioner (family doctor) always receives reports from these specialists.

In $6 \%$ of the subjects the military doctor had to confirm the diabetes information from the conscript, when no written evidence was available at the examination. This confirmation included a formal prescription to the conscript for insulin, a confirmatory telephone call from the treating physician and also by observing signs of cicatrization at injection-sites. If glucosuria was detected in a random urine sample on the day of medical examination by simple reduction testing, a standardized oral glucose tolerance test (OGTT) was subsequently performed by an internist at the Central Military Hospital, using $75 \mathrm{~g}$ load of glucose after an overnight fast. The results of the test were sent to the referring military physician and, if abnormal, also to the local doctor. These procedures have not been changed since 1955 . The results of the OGTT were found in the files of the military registry and all have been interpreted according to the National Institutes of Health criteria by the investigators, the following two criteria established diabetes: 1 . After an overnight fast, ve- 
Table 1. Classification of army conscripts with primary code "diabetes mellitus" or "glucosuria" on medical examination form, total $n=2509$ for the birth cohorts 1960-1970 (inclusive)

\begin{tabular}{lcc}
\hline & $n$ & \% of total \\
\hline $\begin{array}{l}\text { Previous insulin-dependency } \\
\text { manifest } \leq 18 \text { years of age }\end{array}$ & 2136 & 85.1 \\
$\begin{array}{l}\text { Positive urinary reduction } \\
\text { diabetic OGTT }\end{array}$ & & \\
non-diabetic OGTT & 46 & 1.8 \\
Previous diabetic diet and/or & 291 & 11.6 \\
oral hypoglycaemic agents & 36 & 1.4 \\
\hline
\end{tabular}

OGTT = oral glucose tolerance test;

a On follow-up through the local physicians, all were prescribed insulin within 1 year after testing, this was not evaluated for the 36 conscripts reportedly taking hypoglycaemic agents or a diabetic diet

nous glucose concentration $\geq 7.0 \mathrm{mmol} / /$ on at least two separate occasions (and/or), 2. Following $75 \mathrm{~g}$ of oral glucose: venous plasma concentration $\geq 10.0 \mathrm{mmol} / \mathrm{l}$ on at least two occasions during the $2-\mathrm{h}$ test, sampling every $15 \mathrm{~min}$.

Some conscripts are exempted from military service and hence from medical examination because of so-called brother-service: if two older brothers have already completed their military duty, there is exemption for each younger brother. Their percentage, of the total number of annual conscripts, decreased from $6.9 \%$ (birth cohort 1960) to $2.3 \%$ (birth cohort 1970 ), reflecting the tendency towards smaller families. Also, conscripts living in foreign countries, staying in prison (convict), in a psychiatric home, or working in sacerdotal office, may not have had a medical examination at age 18. Further, it is conceivable that other disease states, for example chronic pulmonary disease, were considered sufficient for exemption and that an additional diagnosis of diabetes was not noted. Finally, the military registry is incomplete with regard to death prior to the age of 19 years. However, the mortalityrates of diabetes, both primary and secondary causes, in 0-19-year-old-boys from 1950-1984, were very low and have changed very little [10]. The average death rate with Type 1 diabetes as a primary cause was 2.1/1,000,000 during this time period [11], and thus would have only a marginal effect on the incidence rates.

To determine the degree of ascertainment and from there to estimate the true number of incident cases in the population, the LincolnPeterson capture-recapture method [12] was applied. As a secondary source for validation a former nation-wide actual incidence study was employed of Type 1 diabetes among 0-19-year olds during 1978-1980 [6]. This study obtained data from a questionnaire sent to all physicians involved in the treatment of young diabetic patients, ascertained by sending the same questionnaire to all members of the Dutch Diabetes Association. The degree of ascertainment for paediatricians was $94 \%$ and for internal medicine specialists $75 \%$. The data of the former incidence study (recapture) by questionnaire were collected quite differentlyboth in purpose and in timing from the present one (capture), hence suitable for independent ascertainment.

The capture-recapture method was applied for the birth cohorts of 1960-1970. The older conscript birth cohorts 1955-1958 could not be recaptured by the actual national incidence data, collected during 1978-1980, comprising newly-diagnosed cases aged 0-19 years only. Further the total birth cohort 1959 (January-December) was exempted from military service by national decree.

The matching criteria were date of birth and also, available in $33 \%$, the date of the first administration of insulin.

\section{Statistical analysis}

The Poission regression model was fit into the adjusted cumulative incidence rates using the statistical package GLIM [12]. This was performed to determine if there was a statistically significant increase over time [13]. The risk of developing diabetes under the age of 19 in a population of Dutch males could only be modelled as a function of birth cohorts. Age and calendar time of onset of diabetes could not be modelled because of incomplete data concerning the date of first administration of insulin. The linear model was fitted to the data in the following order [14]. The dependent variable, the adjusted cumulative incidence, was first introduced to the model, second, the independent variable, birth cohort, was fitted to the model, without including a term for trend.

\section{Results}

Table 1 depicts the population initially coded with diabetes or glucosuria in the military registry, $n=2509$. Insulin-dependency before age 19 years was documented in 2136 subjects, born between 1960-1970. In 46 conscripts the finding of a diabetic OGTT was followed by prescribing insulin within 1 year after the finding of positive reduction in the urine at the initial medical military examination. This would represent only $1.8 \%$ of the total population found insulin dependent then.

The descriptive analyses of the ascertainment-adjusted cumulative incidences are shown in Table 2. It appears that the cumulative incidence increased from 1.85 (1960) to $2.12(1970)$. The ascertainment from the previous incidence study into the military records ranged from $75 \%$ to $100 \%$. In the birth cohorts of 1963 and 1969 all cases could be recaptured, for $1962,75 \%$ was found, the average for all birth cohorts was $89.7 \%$. The low rate in the birth cohort of 1962 was the only one significantly different $(p<0.05)$ after adjusting for ascertainment based upon the $95 \%$ confidence intervals, despite its relatively low degree of ascertainment (75\%).

Figure 1 represents the temporal trend of insulin-dependency by the calculated mean annual incidence for each birth cohort by age 18 years. Increases were not always present in each subsequent year of birth, but the overall trend did show an increase in incidence of Type 1 diabetes for birth cohorts of 1960-1970 of 4.4\% annually.

Comparing the deviance with the appropriate degrees of freedom before and after fitting the birth cohorts to the model for linearity revealed that the model itself was not accepted $(p<0.001)$. This implies that although there was

Table 2. Cumulative incidence of Type 1 (insulin-dependent) diabetes mellitus in male army conscripts aged 18 years

\begin{tabular}{llll}
\hline $\begin{array}{l}\text { Year } \\
\text { of } \\
\text { Birth }\end{array}$ & $\begin{array}{l}\text { National } \\
\text { number } \\
\text { of 18-year- } \\
\text { old males }\end{array}$ & $\begin{array}{l}\text { Noted insulin- } \\
\text { dependent } \\
\text { in the } \\
\text { Military Files }\end{array}$ & $\begin{array}{l}\text { Ascertainment } \\
\text { adjusted cumulative } \\
\text { incidence per } 1000 \\
\text { (95\% confidence } \\
\text { intervals) }\end{array}$ \\
\hline 1960 & 119761 & 189 & $1.85(1.60-2.14)$ \\
1961 & 123393 & 167 & $1.76(1.52-2.05)$ \\
1962 & 122783 & 96 & $1.11(0.92-1.35)$ \\
1963 & 125069 & 188 & $1.50(1.30-1.74)$ \\
1964 & 125955 & 198 & $1.83(1.59-2.10)$ \\
1965 & 122978 & 203 & $1.93(1.68-2.21)$ \\
1966 & 119880 & 184 & $1.71(1.48-1.97)$ \\
1967 & 119659 & 219 & $2.07(1.81-2.36)$ \\
1968 & 118716 & 194 & $1.96(1.70-2.26)$ \\
1969 & 124893 & 264 & $2.11(1.87-2.39)$ \\
1970 & 120634 & 234 & $2.12(1.87-2.42)$ \\
\hline
\end{tabular}




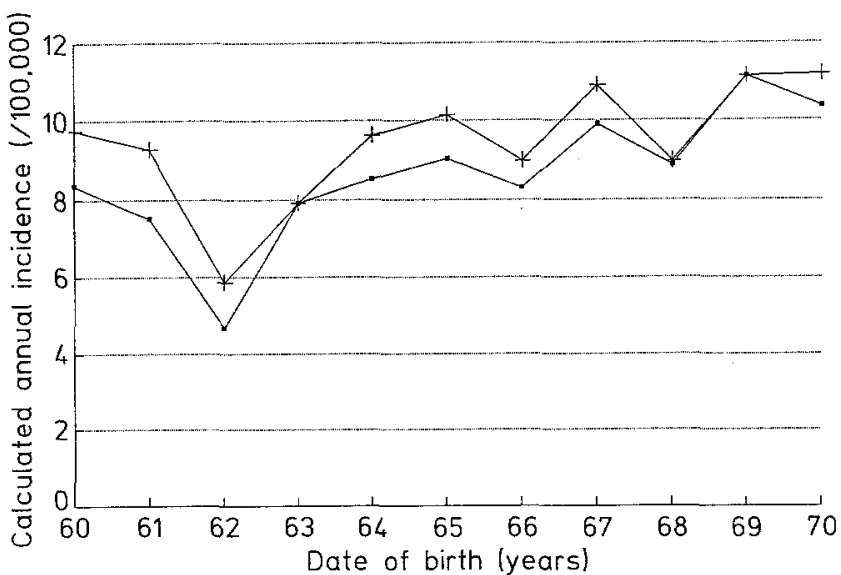

Fig. 1. Temporal trend in the annual cumulative incidence of Type 1 (insulin-dependent) diabetes mellitus in male army conscripts in the Netherlands across birth cohorts, 1960-1978, 1961-1979, etc. Military $(--)$ represents the data from the registry proper, adjusted $(-+-)$ implies the annual cumulative incidence after correction for ascertainment. Overall a non-linear increase in incidence for the birth cohorts $1960-1970$ was observed. A significant $(p<0.05)$ decline for cohort 1962 was seen after adjusting for ascertainment

a significant increase in the incidence of Type 1 diabetes over the total observed period, the increase did not follow a linear trend $(p<0.05)$. The beta coefficient was $1.2 / 1000$ per birth cohort year, or a $4.4 \%$ increased incidence for each yearly birth cohort. Also, after exclusion of the birth cohort 1962 the upward trend remained significant.

\section{Discussion}

The population obtained from conscript data represents a fairly complete nation-wide sample of all Type 1 diabetic males in the Netherlands born between 1960-1970, confirming earlier data from Denmark [7]. A significant nonlinear increase was found in the cumulative incidence of Type 1 diabetes. The overall increase could not be attributed to factors leading to a "false" rise such as underascertainment, improvement of diagnosis or registration, changes in case definition, or disease-associated death.

No appearent slow-down at the end of the present survey was observed. If this trend were to continue, there would be a doubling in incidence every $20-25$ years. This increase in cumulative incidence seems in keeping with the annual increase of $3.3 \%$ in actual incidence [5] observed in other northern European countries for both sexes. It must be understood however that cumulative incidences for birth cohorts are not directly comparable to actual incidences.

Increases in actual incidence have been seen in Sweden [1], Norway [2], Finland [3], New Zealand [5], Austria [16], Denmark [17], France [18], Luxembourg [19] and Poland. Little or no temporal change has been found in Scotland [20], Spain [21], Canada (Montreal, Prince Edward Islands) and in the United States (Allegheny County (Pennsylvania), North Dakota, Colorado and Monroe County (New York State)) [5]. In Leicestershire (United Kingdom) [22] inconsistent trends have been observed. In addition the differences in cross-sectional incidence rates between the different countries remain striking, as in Nordic countries the incidence rate is $20-30 / 100,000$ per year whereas in Japan the rate is $1 / 100,000$ per year [23]. An apparent epidemic of clinical manifestation has been reported from midwestern Poland [24].

On the other hand, a report from the United Kingdom [24] suggested that the overall cumulative incidence of early-onset diabetes has not increased, but that the disease is expressed clinically at an earlier age. Different ways of estimating incidence may well lead to different interpretations with regard to temporal trends [13].

Five previous studies have evaluated temporal trends in Type 1 diabetes by birth cohort. Data from Denmark have indicated a significant rise in incidence for the birth cohorts 1949-1956 [17]. However, studies from the United States [5], Poland [24], Sweden [26] and Finland [27] failed to do so. Given the lack of evidence for effects of birth cohorts found elsewhere, we plan to examine whether the age at which Type 1 diabetes became clinically manifest was different between the present, relatively large birth cohorts and also changes with time across the age groups $(0-18)$. At this point there is no way to decide whether the intruiging dip in cumulative incidence for the 1962 birth cohort was due to chance or associated with features of clinical manifestation.

We confirm that military conscript health data may be considered for monitoring the cumulative incidence of insulin-dependency (and perhaps of other easily defined chronic childhood disorders). It is our impression that the procedures for military service health assessment in the Netherlands is similar to that in other countries and that these procedures have not changed much over time.

Acknowledgements. We thank Dr. A.Green, Odense, Denmark, Chairmen of Eurodiab subarea A for epidemiologic studies, for his critical reading of the manuscript and Mrs. J.Drost-v.d. Linden and Mrs. M. Huls-van Vliet for secretarial help. The study was supported by the Dutch Diabetes Research Fund, the Child Health and Wellbeing Fund, Rotterdam and the National Institutes of Health, grant DK 24021. CEMD received a student travel grant from the State University of Groningen (Prof. HSA Heijmans, Department of Paediatrics).

\section{References}

1. Dahlquist G, Blom L, Holmgren G et al. (1985) The epidemiology of diabetes in Swedish children $0-14$ years - a six year prospective study. Diabetologia 28: 802-808

2. Joner G, Søvik O (1989) Increasing incidence of diabetes mellitus in Norwegian children 0-14 years of age 1973-1982. Diabetologia 32: 79-83

3. Reunanen A, Åkerblom HK, Käär ML (1982) Prevalence and ten year (1970-1979) incidence of insulin-dependent diabetes mellitus in children and adolescents in Finland. Acta Pediatr Scand 71:893-899

4. Tuomilehto J, Rewers M, Reunanen A et al. (1991) Increasing trend in Type 1 (insulin-dependent) diabetes mellitus in childhood in Finland. Diabetologia 34: 282-287

5. Diabetes Epidemiology Research International Group (1990) Secular trends in incidence of childhood insulin-dependent diabetes (IDDM) in ten countries. Diabetes 39: 858-864 
6. Vaandrager GJ, Bruining GJ, Veenhof FJ, Drayer NM (1984) Incidence of childhood diabetes in the Netherlands: a decrease from north to south over North-Western Europe. Diabetologia 27: 203-206

7. Vaandrager GJ, Van Ormondt M, Bruining GJ (1988) Increasing prevalence of diabetes mellitus in male army conscripts, aged 18. Diab Res Clin Practice 5 [Suppl 1]: 634

8. Green A, Hauge M, Holm NV, Rasch LL (1980) Epidemiological studies of diabetes mellitus in Denmark: 1. A case finding method based on the National Service Conscript Registry. Diabetologia 19: 355-358

9. Green A, Andersen PK (1983) Epidemiological studies of diabetes mellitus in Denmark: 3 . Clinical characteristics and incidence of diabetes among males aged 0 to 19 years. Diabetologia 25:226-230

10. Death according to causes by death certificates, age and sex, 1940-1980. Annual Reports 1941-1981. Central Office for Statistics, Voorburg, The Netherlands

11. Vaandrager GJ, Meijer WJ (1987) Mortality at onset of insulindependent diabetes mellitus in the young (0-19 years) in the Netherlands 1978-1980 (abstract in English). Ned Tijdschr Geneeskd 131:13

12. Bishop YMM, Fienberg SE, Holland PW (1978) Estimating the size of a closed population. Discrete multivariate analysis, 5 th ed. MIT, Cambridge, pp 229-256

13. Breslow NE, Day NE (1987) Statistical methods in cancer research. Vol. II. The design and analysis of cohort studies. 1 ARC Scientific Publications, no.82, International Agency for Research on Cancer, Lyon, pp 53-55

14. Baker RJ, Nelder JA (1985) GLIM (Generalized Linear Interactive Modeling). Release 3.77 update 1. Royal Statistical Society, London

15. Rewers M, Stone RA, LaPorte RE et al. (1989) Poisson regression modelling of temporal trends in incidence of childhood insulin-dependent diabetes mellitus in Allegheny County, Pennsylvania and Wielkopolske, Poland, 1970-1975. Am J Epidemiol 129: $569-581$

16. Schober E, Frish H (1988) Incidence of childhood diabetes in Austria 1979-1984. Acta Pediatr Scand 77:299-302

17. Mølbak AG, Nørgaard K, Christau B, Kjær M, Nerup J (1987) Incidence of Type 1 (insulin-dependent) diabetes mellitus in Denmark - evidence of secular trend. Diabetologia 30: 559 A (Abstract)
18. Levy-Marchal C, Papoz L, de Beaufort C et al. (1990) Incidence of juvenile Type 1 (insulin-dependent) diabetes mellitus in France. Diabetologia 33: 465-469

19. de Beaufort CE, Michel G, Glaesener G (1988) The incidence of Type 1 (insulin-dependent) diabetes mellitus in subjects aged 0 19 years in Luxembourg: a retrospective study from 1977 to 1986. Diabetologia 31: 758-761

20. Patterson CC, Smith PG, Webb J, Heasman MA, Mann JI (1988) Geographical variation in the incidence of diabetes mellitus in Scottish children during the period 1977-1983. Diab Med 5: 160 165

21. Serrano Ríos M, Moy CS, Martín Serrano R et al. (1990) Incidence of Type 1 (insulin-dependent) diabetes mellitus in subjects 0-14 years of age in the Comunidad of Madrid, Spain. Diabetologia 33: 422-424

22. Burden AC, Hearnshaw JR, Swift WGF (1989) Childhood diabetes mellitus: an increasing incidence. Diab Med 6:334-336

23. Diabetes Epidemiology Research International Group (1988) Geographic patterns of childhood insulin-dependent diabetes mellitus. Diabetes 37: 8-13

24. Rewers M, LaPorte RE, Walczak M, Dmochowski K, Bogaczynska $\mathrm{E}$ (1987) Appearent epidemic of insulin dependent diabetes in Midwestern Poland. Diabetes 36: 1-14

25. Kurtz Z, Peckham CS, Ades AE (1988) Changing prevalence of juvenile-onset diabetes mellitus. Lancet II: $88-90$

26. Nyström L, Dahlquist G, Rewers M, Wall S (1990) The Swedish childhood diabetes study. An analysis of the temporal variation in diabetes incidence 1978-1987. Int J Epidemiol 19: 141-146

27. Reunanen A, Åkerblom HK (1986) A national drug register as a data source in the study of the epidemiology of IDDM children in Finland. In: Serrano-Rios M, Lefèbvre PJ (eds) Diabetes, 1985. Elsevier, Amsterdam, pp 408-412

Received: 11 June 1991

and in revised form: 27September 1991

Dr. G.J. Bruining

Sophia Children's Hospital

P.O.Box 70029

NL-3000 LL Rotterdam

The Netherlands 